\title{
NOHUT SAMANI TARLA ATIĞININ SULU ÇÖZELTİLERDEN METÍLEN MAVİSİ GİDERİMİNDE DÜŞÜK MALİYETLİ BİYOSORBENT OLARAK DEĞERLENDİRİLMESİ
}

\author{
Murat KILIÇ*, Özge ÇEPELIOĞULLAR**, Gamzenur ÖZSİN*, \\ Başak Burcu UZUN*, Ayşe E. PÜTÜN* \\ "Kimya Mühendisliği Bölümü, Mühendislik Fakültesi, Anadolu Üniversitesi, 26555 Eskişehir, Türkiye \\ *** Kimya Mühendisliği Bölümü, Kimya-Metalurji Fakültesi, İstanbul Teknik Üniversitesi, 34469, İstanbul, \\ Türkiye \\ mkilic3@anadolu.edu.tr, cepeliogullar@itu.edu.tr, gozsin@anadolu.edu.tr, bbuzun@anadolu.edu.tr, \\ aeputun@anadolu.edu.tr
}

(Geliş/Received: 10.06.2013; Kabul/Accepted: 04.09.2014)

\section{ÖZET}

Yapılan bu çalışmada tarımsal bir atık olan nohut samanı, sulu çözeltilerden boyar madde gideriminde biyosorbent olarak değerlendirilmiştir. Çözelti pH'ı, biyosorbent miktarı, başlangıç boyar madde derişimi, temas süresi ve çözelti sıcaklığının biyosorpsiyon işlemine olan etkileri incelenmiştir. Ayrıca, metilen mavisi biyosorpsiyonuna ait denge izoterm, termodinamik ve kinetik çalışmalar gerçekleştirilmiştir. Biyosorpsiyon denge verilerinin Freundlich izotermi ile uyumlu olduğu belirlenmiş, biyosorpsiyonu en iyi ifade edebilen kinetik modelin ise sözde(yalancı) ikinci dereceden model olduğu saptanmıştır. Hesaplanan termodinamik parametreler, biyosorpsiyonun $20-50{ }^{\circ} \mathrm{C}$ aralığında kendiliğinden gerçekleşen endotermik bir işlem olduğunu göstermiştir. Metilen mavisi biyosorpsiyonu için nohut samanının maksimum tek tabaka biyosorpsiyon kapasitesi $108,7 \mathrm{mg} / \mathrm{g}$ olarak belirlenmiştir. Sonuç olarak, nohut samanının sulu çözeltilerden metilen mavisi gideriminde çevreye dost, düşük maliyetli ve etkili bir biyosorbent olarak kullanılabileceği belirlenmiştir.

Anahtar Kelimeler: Biyosorpsiyon, boyar madde, nohut samanı, izoterm, kinetik, termodinamik

\section{EVALUATION OF FIELD DEBRIS OF CHICKPEA HUSK AS A LOW-COST BIOSORBENT FOR REMOVAL OF METHYLENE BLUE FROM AQUEOUS SOLUTIONS}

\begin{abstract}
In the present study, an important agricultural waste, chickpea straw, was evaluated as biosorbent material for the removal of basic dyes from aqueous solutions. Effects of solution $\mathrm{pH}$, biosorbent dosage, initial dye concentration, contact time and solution temperature on biosorption process were investigated. In addition, equilibrium, kinetic and thermodynamic studies were carried out for the methylene blue biosorption. It was determined that equilibrium data were in accordance with Freundlich isotherm and pseudo second order kinetic model was the best model to express the biosorption kinetics. Calculated thermodynamic parameters showed that, biosorption was a spontaneous endothermic process between 20 and $50{ }^{\circ} \mathrm{C}$. The maximum monolayer biosorption capacity of chickpea husk was determined as $108.7 \mathrm{mg} / \mathrm{g}$ for methylene blue biosorption. As a result, chickpea straw could be used as an environmentally friendly, cheap and effective biosorbent material for the removal of methylene blue from aqueous solutions.
\end{abstract}

Keywords: Biosorption, dye, chickpea straw, isotherm, kinetics, thermodynamics 


\section{GÍRISŞ (INTRODUCTION)}

Sentetik boyar maddeler; plastik, kozmetik, tekstil gibi birçok sektörde kullanılan ve atık sular için önemli tehdit oluşturan maddelerin başında gelmektedir. Boyar maddeler, oldukça karmaşı bir organik yapıya sahip olmaları dolayısıyla ısıya, ışığa ve oksitlenmeye karşı oldukça dayanıklıdırlar [1]. Bu nedenle, doğada bozunmaları oldukça uzun zaman almakta ve düşük derişimlerde bile atık sularda ciddi problemlere yol açmaktadırlar [2]. Atık sulardan boyar madde gideriminde filtreleme, iyon değişimi, koagülasyon, oksidasyon, ters osmoz, adsorpsiyon gibi birçok fiziksel, kimyasal veya biyolojik yöntem kullanılmaktadır [3]. Adsorpsiyon, sulardan kirleticileri uzaklaştırmada etkin bir giderme yöntemi olmasının yanı sıra kullanılan adsorbentin çevre dostu, ucuz ve kolay bulunabilir olmasından ötürü ekonomik bir yöntem olarak bilinmektedir [4,5]. Tarımsal atıklar, orman endüstrisi artıkları, bakteri ve mantar gibi biyosorbentlerin kullanıldığı biyosorpsion işlemlerinde, ticari adsorbentler kadar etkili boyar madde giderimi gerçekleştirilebilmektedir.

Türkiye, tarımsal ürün açısından oldukça zengin bir çeşitliliğe sahiptir ve her y1l, hasat sonrası ciddi miktarda tarımsal atık tarlalarda kalmaktadır. $\mathrm{Bu}$ atıkların yakılarak yol edilmesi yerine farklı ve alternatif teknolojiler ile değerlendirilmesinin sağlanabilmesi ise atık yönetimi açısından son derece önem taşımaktadır. Ülkemiz dünya nohut üretiminde ilk beş ülke arasında yer almaktadır [6,7]. Bu nedenle sunulan çalışmada nohut samanı atıkları, sulu çözeltilerden boyar madde gideriminde biyosorbent olarak değerlendirilmiştir. Boyar madde olarak ise kağıt, kumaş, ipek ve yün boyama da oldukça sık kullanılan metilen mavisi [8] tercih edilmiştir. Böylece nohut samanı gibi tarımsal atıkların, herhangi bir 1sıl ve kimyasal işlem görmeksizin sulu çözeltilerden organik kirleticilerin gideriminde kullanılabileceği belirlenmiştir.

\section{DENEYSEL ÇALIŞMALAR (EXPERIMENTAL WORK)}

Çalışmada kullanılan nohut samanı, İç Anadolu Bölgesi'nden temin edilmiştir. Hammadde, oda sıcaklı̆ğında kurutulmuş, parçacık boyutunu küçültmek amacıyla değirmende öğütülüp, elenmiştir. Biyosorpsiyon deneylerinde parçacık boyutu aralığı olarak 0,112-0,224 mm kullanılmıștır. Calışmada kullanılan boya çözeltileri, $1000 \mathrm{mg} / \mathrm{L}$ 'lik derişimde hazırlanan stok çözeltiden seyreltilerek elde edilmiştir. Kullanılan metilen mavisi Merck(52015) firmasında temin edilmiștir. Çözeltilerin pH'ını ayarlayabilmek amaciyla $0,01 \mathrm{~mol} / \mathrm{L} \mathrm{NaOH}$ ve $\mathrm{HCl}$ derişimindeki çözeltiler kullanılmıştır. Sulu çözeltilerden boyar madde gideriminde, her bir deneyde $200 \mathrm{~mL}$ 'lik çözeltiler kullanılmıştır. Tüm deneyler, 20 ile $50{ }^{\circ} \mathrm{C}$ sicaklık aralığında ve $120 \mathrm{rpm}$ karıştırma hızında yürütülmüştür. Çözeltilerden 240 dakikaya kadar değişen zaman aralıklarında, eşit miktarlarda $(5 \mathrm{~mL})$ örnek alınarak santrifüjlenmiştir. Santrifüj işleminden sonra, çözelti süzülmüş ve kalan çözelti UV spektrofotometresinde $664 \mathrm{~nm}$ dalga boyunda analiz edilmiştir. Birim biyosorbent başına dengede $\left(\mathrm{q}_{\mathrm{e}}\right)$ ve belli bir zamanda tutulan boyar madde miktarı $\left(\mathrm{q}_{\mathrm{t}}\right)$ ile biyosorplanan boyar madde yüzdesi(biyosorpsiyon verimi) aşağıda verilen eşitlikler kullanılarak hesaplanmıştır.

$$
\begin{aligned}
& q_{e}=\frac{\left(C_{i}-C_{e}\right) \mathrm{V}}{W} \\
& q_{t}=\frac{\left(C_{i}-C_{t}\right) \mathrm{V}}{W}
\end{aligned}
$$

Biyosorpsiyon verimi $(\%)=\frac{\left(C_{i}-C_{e}\right)}{C_{i}} \times 100$

\section{SONUCLAR VE TARTISMA (RESULTS AND DISSCUSSION)}

\section{1. pH'ın Etkisi (Effect of pH)}

$\mathrm{pH}$, sulu çözeltilerde bulunan $\mathrm{H}^{+}$ve $\mathrm{OH}^{-}$iyonlarının, katı parçacıklar üzerine tutunabilme özelliğini etkilemesinden ötürü biyosorpsiyon işleminde göz önünde bulundurulması gereken önemli parametrelerden biridir [1]. Çözelti pH'ının, biyosorpsiyona etkisini belirleyebilmek amaciyla, pH'1 3-9 aralığında değişen çözeltiler kullanılarak deneyler gerçekleştirilmiş ve sonuçlar Şekil 1'de verilmiştir. Düşük çözelti $\mathrm{pH}$ 'larında, $\mathrm{H}^{+}$iyonlarının katı yüzeyine tutunma eğiliminde olmalarından dolayı, metilen mavisinin biyosorbent tarafindan tutunma verimi olumsuz yönde etkilenmektedir. Yüksek pH'lar da ise, katı yüzeyin negatif olarak yüklenmesinden dolayı oluşan elektrostatik kuvvetlerden dolayı tutunma verimi artmaktadır[8]. Deneysel sonuçlara göre metilen mavisi gideriminde, en uygun çözelti $\mathrm{pH}^{\prime}{ }_{1} 7$ olarak belirlenmiştir. Çözeltinin pH'ının 7'yi geçmesi durumunda ise metilen mavisi tutunma miktarında gözlemlenen azalma, farklı biyosorbentler ile yapilan benzer çalışmalarda da göze çarpmaktadır $[9,10]$. Metilen mavisinin $\mathrm{pH} 7$ 'den sonraki artan $\mathrm{pH}$ değerlerinde gideriminin azalması ise biyosorbent yüzeyinde bulunan fonksiyonel grupların çözeltiye geçerek, yüzey özelliklerini değiştirmesi ve yüzeyde pozitif yüklenmiş bölgelerin oluşmasından kaynaklanmaktadır [11]. Ayrıca, metilen mavisi yapısında bulunan $\mathrm{Cl}^{-}$iyonunun çok yüksek $\mathrm{pH}$ değerlerinde, $\mathrm{NaOH}$ ile yer değiştirme reaksiyonuna girip, $\mathrm{NaCl}$ tuzunu oluşturmasından dolayı da biyosorpsiyon kapasitesinde azalmaya neden olduğu bilinmektedir [12]. 

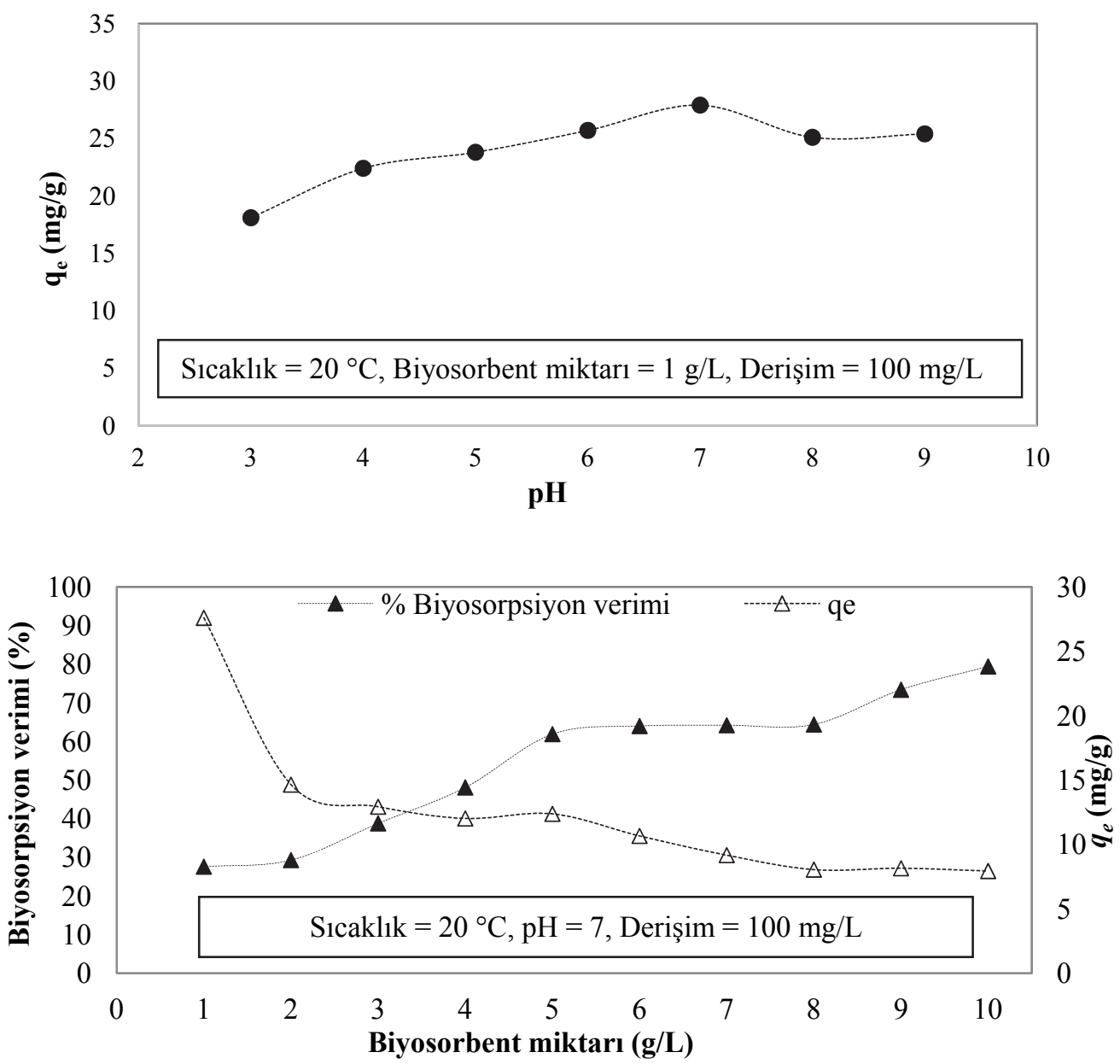

Şekil 1. Çözelti pH'ı (a) ve biyosorbent miktarının (b) biyosorpsiyon işlemine etkisi (Effect of solution pH (a) and biosorbent dosage (b) on biosorption process)

\subsection{Biyosorbent Miktarının Etkisi (Effect of Biosorbent Dosage)}

Çözeltiye eklenecek olan biyosorbent miktarı, adsorplanacak boyar madde miktarının verimini etkileyen önemli faktörlerden biridir. Kullanılacak biyosorbent miktarının az olması durumunda, gerçekleşebilecek maksimum biyosorpsiyon verimi azalabilir. Çözeltiye fazla miktarda biyosorbent eklenmesi durumunda ise, çözelti içinde topaklanmalar meydana gelip, biyosorpsiyon verimini olumsuz yönde etkileyebilir [13]. Biyosorbent miktarının etkisini belirlemek amacıyla deneyler, 1-10 $\mathrm{g} / \mathrm{L}$ aralığında gerçekleştirilmiş ve elde edilen deneysel sonuçlar Şekil 1'de verilmiştir. Çalışılan biyosorbent miktarı aralığı, literatürde farklı adsobentler ile yapılan çalışmalar $[14,15]$ ile karşılaştırıldığında, literatür ile uyumlu olduğunu, nohut samanının boyar madde giderimi işlemlerinde ekonomik olarak uygulanabilirliğini göstermektedir. Kullanılan biyosorbent miktarının artması ile nohut samanı üzerine tutulan boyar madde miktarının arttığ belirlenmiştir. Fakat birim biyosorbent başına tutulan boyar madde miktarları incelendiğinde $\left(\mathrm{q}_{\mathrm{e}}\right)$, aslında artan biyosorbent miktarı ile boyar madde gideriminin azaldığı görülmektedir. Bu durum biyosorbent miktarı arttıkça parçacıkların topaklanmasından dolayı sorbatın tutunacağı temas yüzeyinin azalmasından kaynaklanmaktadır. Bu nedenle, metilen mavisi gideriminde en uygun biyosorbent miktarının $5 \mathrm{~g} / \mathrm{L}$ olduğu belirlenmiştır.

3.3. Başlangıç Boyar Madde Derişimi ve Temas Süresinin Sıcaklığa Bağlı Biyosorpsiyona Etkisi (Effect of Initial Dye Concentration and Contact Time on Temperature-dependent Biosorption)

Başlangıç boyar madde derişimi ve temas süresinin biyosorpsiyona etkisi, 100-400 $\mathrm{mg} / \mathrm{L}$ boyar madde derişimi, 10-240 dak temas süresi ve $20-50{ }^{\circ} \mathrm{C}$ sıcaklık aralıklarında incelenmiştir. Şekil 2'de başlangıç boyar madde derişimi ve temas süresinin farklı çözelti sıcaklıklarında, biyosorpsiyon verimine olan etkisini gösteren deneysel sonuçlar verilmiştir. Buna göre, çözeltideki boyar madde derişimi arttıkça sistemin biyosorpsiyon kapasitesinin $\left(\mathrm{q}_{\mathrm{e}}\right)$ kullanımının arttığ 1 belirlenmiştir. 

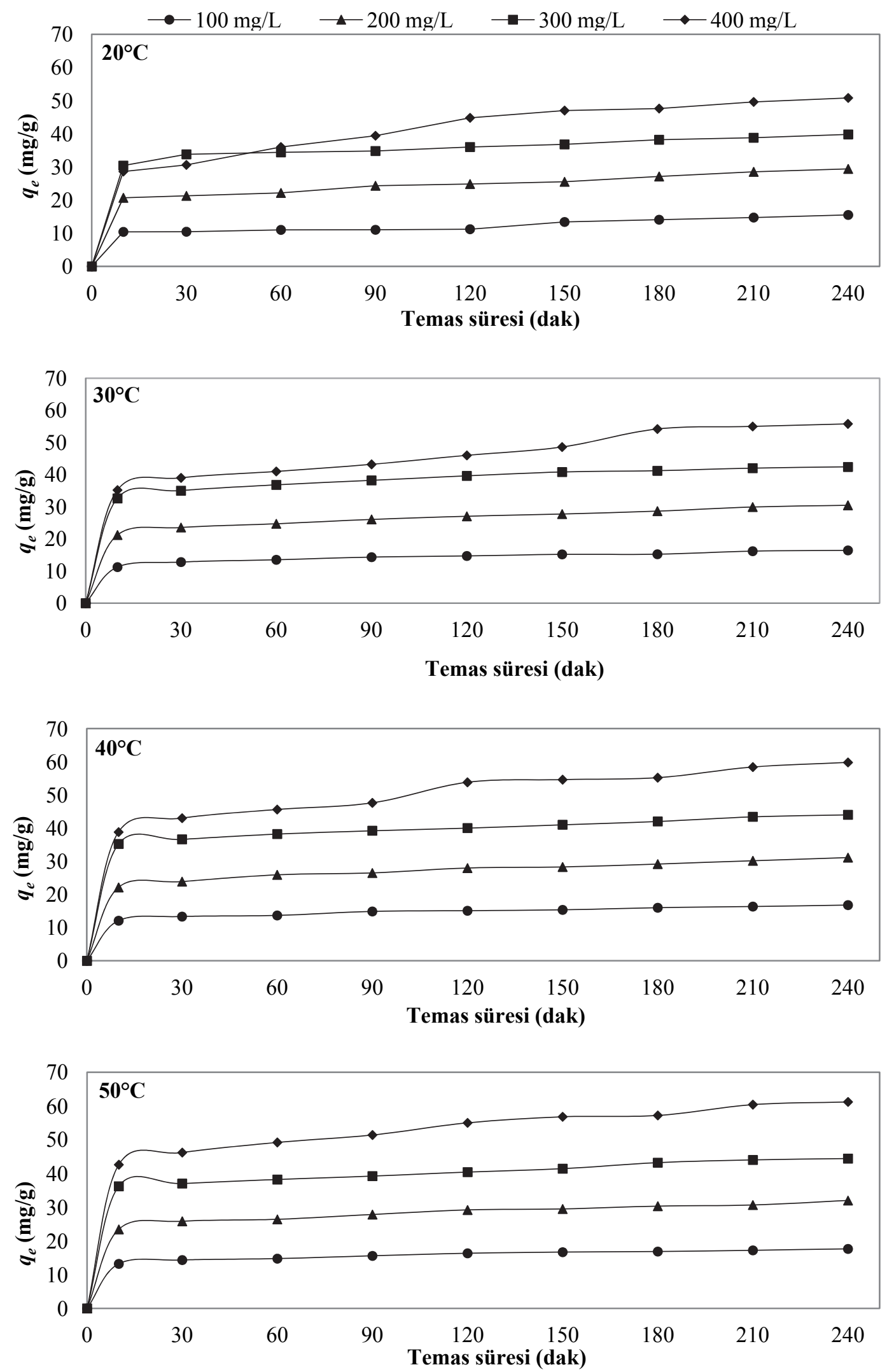

Şekil 2. Başlangıç boyar madde derişimi ve temas süresinin farklı sıcaklıklarda metilen mavisi giderimine etkisi ( $\mathrm{pH}=7$, Biyosorbent miktarı $=5 \mathrm{~g} / \mathrm{L}$ ) (Effect of initial dye concentration and contact time on methylene blue removal at different temperatures $(\mathrm{pH}=7$, Biosorbent dosage $=5 \mathrm{~g} / \mathrm{L}))$ 
Başlangıç boyar madde derişimi, çözeltide bulunan iyonlar ve katı biyosorbent parçacıkları arasında meydana gelecek olan kütle aktarımında itici güç olarak önemli bir rol oynamaktadır. Sıvı fazdaki başlangıç derişiminin artması, katı ve sıvı faz arasındaki derişim farkının artmasına yol açar ve sıvı fazdan katı faza kütle transferinin artmasına neden olur [16]. Bu nedenle başlangıç metilen mavisinin derişiminin $100 \mathrm{mg} / \mathrm{L}$ 'den $400 \mathrm{mg} / \mathrm{L}$ 'ye arttırılması, giderim miktarında dört kattan fazla artışa sebep olmuştur. Bu artış, özellikle $50{ }^{\circ} \mathrm{C}$ 'de gerçekleştirilen deneylerde, sicaklık etkisiyle de daha belirgin hale gelmiştir. Deneysel sonuçlara göre, artan sicaklıkla birlikte boyar madde gideriminin de $\operatorname{artt1ğ} 1$ saptanmıştır. Metilen mavisi moleküllerinin hareket kabiliyeti sıcaklıkla artmış ve bu durum, boyar maddenin biyosorbent üzerine daha rahat tutunmasina neden olmuştur. Temas süresi de boyar madde iyonlarının katı parçacıklar üzerine tutunabilmeleri için ve bu işlemin tam kapasite ile gerçekleştirilebilmesi açısından bir diğer önemli parametredir. Çözeltideki metilen mavinin büyük bir bölümünün ilk 30 dakika içerisinde giderildiği ve sistemin 180 dakikalık temas süresi sonunda, boyar madde açısından belli bir doygunluğa ulaşarak, dengeye yaklaştığı tespit edilmiştir. Temas süresinin çok uzun olması durumunda ise biyosorbent belli bir doygunluğa ulaştığından ötürü katı yüzeyine tutunan boyar madde miktarı 180 dakika sonrasında kayda değer bir artış göstermemiştir.

\subsection{Denge İzotermleri ve Kinetik Çalışmalar (Equilibrium Isotherms and Kinetic Studies)}

Boyar madde gideriminde kullanılan biyosorpsiyon işleminin uyduğu izoterm modelini belirleyebilmek amacıyla yapılan deneysel çalışmadan elde edilen veriler, Langmuir (L) [17], Freundlich (F) [18] ve Dubinin-Radushkevich (D-R) [19] izotermleri kullanılarak modellenmiştir. Ayrıca, biyosorpsiyonun kinetik mekanizmasını belirleyebilmek amacıyla elde edilen veriler, sözde 1. Dereceden [20], sözde 2 . Dereceden [21] ve partikül içi difüzyon [22] kinetik modelleri yardımıyla değerlendirilmiştir. Kullanılan izoterm ve kinetik model denklemleri Tablo 1'de özetlenmiştir.

Tablo 1. İzoterm ve Kinetik Model Eșitlikleri (Isotherm and Kinetic Model Equations)

\begin{tabular}{|c|c|c|c|}
\hline Model & Denklem & Doğrusal Denklem & Parametre \\
\hline Langmuir & $q_{e}=\frac{q_{m} K_{L} C_{e}}{1+K_{L} C_{e}}$ & $\frac{C_{e}}{q_{e}}=\frac{1}{q_{m} K_{L}}+\frac{C_{e}}{q_{m}}$ & $\begin{array}{l}\mathrm{q}_{\mathrm{e}}(\mathrm{mg} / \mathrm{g}) \text { : denge durumundaki } \\
\text { biyosorpsiyon kapasitesi } \\
\mathrm{q}_{\mathrm{m}}(\mathrm{mg} / \mathrm{g}) \text { : Langmiur biyosorpsiyon } \\
\text { kapasitesi } \\
\mathrm{C}_{\mathrm{e}}(\mathrm{mg} / \mathrm{L}) \text { : denge durumundaki çözeltideki } \\
\text { boyar madde derişimi } \\
\mathrm{K}_{\mathrm{L}}(\mathrm{L} / \mathrm{mg}) \text { : Langmiur biyosorpsiyon sabiti }\end{array}$ \\
\hline Freundlich & $q_{e}=K_{F} C_{e}^{1 / n}$ & $\ln q e=\ln K_{F}+\frac{1}{n} \ln C_{e}$ & $\begin{array}{l}\mathrm{n} \text { : biyosorpsiyon şiddetiyle ilgili } \\
\text { maddenin heterojenliği ile değişen empirik } \\
\text { sabit, (birimsiz) } \\
\mathrm{K}_{\mathrm{F}}\left((\mathrm{mg} / \mathrm{g})(\mathrm{L} / \mathrm{mg})^{1 / \mathrm{n}}\right) \text { : Freundlich } \\
\text { biyosorpsiyon sabiti }\end{array}$ \\
\hline D-R & $q_{e}=q_{m} \exp \left(-\beta \varepsilon^{2}\right)$ & $\begin{array}{c}\ln q_{e}=\ln q_{m}-\beta \varepsilon^{2} \\
\varepsilon=R T\left[1+\frac{1}{C_{e}}\right] \text { ve } E=\frac{1}{\sqrt{2 \beta}}\end{array}$ & $\begin{array}{l}\beta\left(\mathrm{mol}^{2} / \mathrm{kJ}^{2}\right): \text { biyosorpsiyon enerjisi sabiti } \\
\varepsilon: \text { Polanyi potansiyeli } \\
\mathrm{R}(8.314 \mathrm{~J} /(\mathrm{mol} \mathrm{K})) \text { : evrensel gaz sabiti } \\
\mathrm{T}(\mathrm{K}): \text { mutlak sicaklık } \\
\mathrm{E}(\mathrm{kJ} / \mathrm{mol}) \text { : ortalama serbest enerji }\end{array}$ \\
\hline $\begin{array}{l}\text { Sözde } \\
\text { 1.derece }\end{array}$ & $\frac{d q_{t}}{d t}=k_{1}\left(q_{e}-q_{t}\right)$ & $\log \left(q_{e}-q_{t}\right)=\log \left(q_{e}\right)-\frac{k_{1} t}{2.303}$ & $\begin{array}{l}\mathrm{q}_{\mathrm{e}}(\mathrm{mg} / \mathrm{g}) \text { : denge durumundaki } \\
\text { biyosorpsiyon kapasitesi } \\
\mathrm{q}_{\mathrm{t}}(\mathrm{mg} / \mathrm{g}): \mathrm{t} \text { anındaki biyosorpsiyon } \\
\text { kapasitesi } \\
\mathrm{t}(\text { dak): temas süresi } \\
\mathrm{k}_{1}(1 / \text { dak): sözde } 1 . \text { dereceden kinetik hız } \\
\text { sabiti }\end{array}$ \\
\hline $\begin{array}{l}\text { Sözde } \\
\text { 2. derece }\end{array}$ & $\frac{d q_{t}}{d t}=k_{2}\left(q_{e}-q_{t}\right)^{2}$ & $\frac{t}{q_{t}}=\frac{1}{k_{2} q_{e}^{2}}+\frac{1}{q_{e}} t$ & $\begin{array}{l}\mathrm{q}_{\mathrm{t}}(\mathrm{mg} / \mathrm{g}) \text { : } \mathrm{t} \text { anındaki biyosorpsiyon } \\
\text { kapasitesi } \\
\mathrm{k}_{2} \text { (g/mg.dak): sözde 2.dereceden kinetik } \\
\text { hiz sabiti }\end{array}$ \\
\hline $\begin{array}{l}\text { Partikül } \\
\text { içi } \\
\text { difüzyon }\end{array}$ & $q_{t}=k_{p} t^{1 / 2}+C$ & $q_{t}=k_{p} t^{1 / 2}+C$ & $\begin{array}{l}\mathrm{q}_{\mathrm{t}}(\mathrm{mg} / \mathrm{g}): \mathrm{t} \text { anındaki biyosorpsiyon } \\
\mathrm{kapasitesi} \\
\mathrm{k}_{\mathrm{p}}\left(\mathrm{mg} / \mathrm{g} \text { dak }^{1 / 2}\right) \text { : partikül içi kinetik } \\
\text { modele ait hız sabiti } \\
\mathrm{C}: \text { kesim noktası }\end{array}$ \\
\hline
\end{tabular}


İzoterm modellerine ait sabit katsayılar ve regresyon sayıları $\left(\mathrm{R}^{2}\right)$, oluşturulan lineer doğrular yardımıyla hesaplanmış ve farklı sıcaklıklar için elde edilen sonuçlar Tablo 2'de verilmiştir. Aynı zamanda bu çalışmada kullanılan izoterm modellerinin deneysel veriler ile uyumu Şekil 3'de gösterilmiştir. $\mathrm{R}^{2}$ değerinin 1'e yaklaşarak artması, deneysel olarak elde edilen ve model ile tahmin edilen değerlerin arasında büyük bir korelasyon olduğunu belirtmektedir [23]. Tablo 2'de verilmiş olan $\mathrm{R}^{2}$ değerinden ve Şekil 3'den anlaşılacağı üzere, Freundlich modelinin diğer modellere göre deneysel verilerle daha uyumlu olduğu belirlenmiştir. Bu nedenle metilen mavisinin çalışılan koşullarda, nohut samanı üzerine çok tabakalı bir şekilde tutunduğu ve biyosorbent yüzeyinin de heterojen olduğu sonucuna ulaşılabilir. Ayrıca, Langmuir modeli kullanılarak hesaplanan $\mathrm{R}_{\mathrm{L}}$ yani ayırma faktörü değerlerinin $0,44-0,64$ aralığında olduğunun belirlenmesi ile metilen mavisinin nohut samanı üzerine biyosorpsiyonun uygun olduğu söylenebilir. Metilen mavisi biyosorpsiyonu için nohut samanının maksimum tek tabaka biyosorpsiyon kapasitesi ise 108,7 mg/g olarak hesaplanmıştır.

Tablo 3'de çalışmada kullanılan nohut samanının biyosorpsiyon kapasitesinin, literatürde metilen mavisi giderimi için farklı biyokütleler kullanılarak yapılan çalışmalarla karşılaştırması verilmiştir.
Tablo 2. Metilen mavisi biyosorpsiyonuna ait izoterm parametreleri (Isotherm parameters for the methylene blue biosorption)

\begin{tabular}{cccccc}
\hline Model & & \multicolumn{4}{c}{ Sicaklık $\left({ }^{\circ} \mathbf{C}\right)$} \\
\hline & & $\mathbf{2 0}$ & $\mathbf{3 0}$ & $\mathbf{4 0}$ & $\mathbf{5 0}$ \\
\cline { 3 - 6 } & $\mathrm{q}_{\mathrm{m}}$ & 101,01 & 103,09 & 107,52 & 108,70 \\
$\mathrm{~L}$ & $\mathrm{~K}_{\mathrm{L}}$ & 0,0055 & 0,0077 & 0,0077 & 0,0103 \\
& $\mathrm{R}^{2}$ & 0,8962 & 0,8823 & 0,8933 & 0,9072 \\
& $\mathrm{R}_{\mathrm{L}}$ & 0,642 & 0,564 & 0,563 & 0,490 \\
& & & & & \\
& $\mathrm{~K}_{\mathrm{F}}$ & 1,258 & 2,081 & 2,076 & 3,507 \\
$\mathrm{~F}$ & $\mathrm{n}$ & 1,383 & 1,511 & 1,487 & 1,747 \\
& $\mathrm{R}^{2}$ & 0,9912 & 0,9933 & 0,9951 & 0,9763 \\
& & & & & \\
& $\mathrm{q}_{\mathrm{m}}$ & 41,99 & 43,52 & 44,51 & 44,21 \\
$\mathrm{D}-\mathrm{R}$ & $\beta$ & $2 \times 10^{-4}$ & $7 \times 10^{-5}$ & $7 \times 10^{-5}$ & $3 \times 10^{-5}$ \\
& $\mathrm{E}$ & 0,05 & 0,084 & 0,084 & 0,129 \\
& $\mathrm{R}^{2}$ & 0,9230 & 0,8365 & 0,8431 & 0,7939 \\
\hline
\end{tabular}

Diğer tarımsal atıklarla karşılaştırıldığında, nohut samanının metilen mavisi gideriminde etkin bir biyosorbent olduğu görülmektedir.

Boyar maddelerin adsorpsiyonu, boya moleküllerinin sınır tabakasına difüzyonu, partikül içi difüzyonu ve sorbent yüzeyine adsorpsiyonu olmak üzere üç

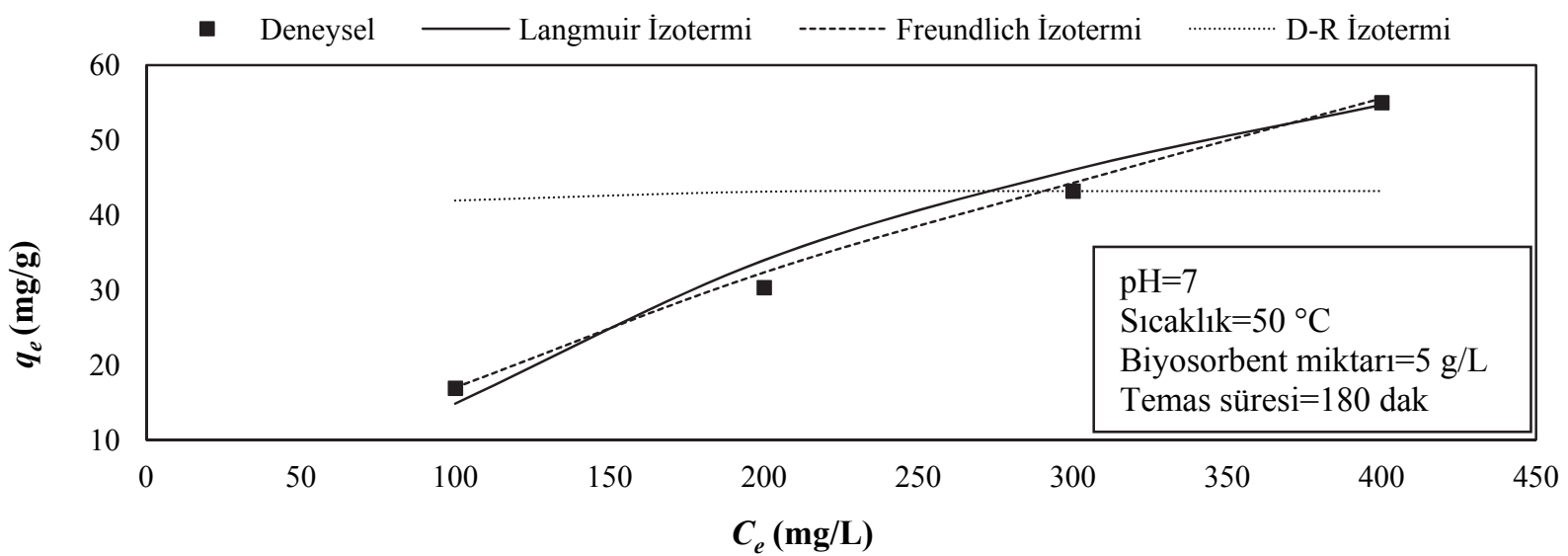

Şekil 3. İzoterm modellerinin deneysel veriler ile uyumu (Fitting of isotherm models with the experimental data)

Tablo 3. Nohut samanı biyosorpsiyon kapasitesinin karşılaştırması (Comparison of chickpea straw biosorption capacity)

\begin{tabular}{|c|c|c|c|c|c|c|c|}
\hline \multirow[b]{2}{*}{ Biyosorbent } & \multicolumn{5}{|c|}{ Çalışma koşulları } & \multirow[b]{2}{*}{$\underset{(\mathrm{mg} / \mathrm{g})}{\mathbf{q}_{\mathrm{m}}}$} & \multirow[b]{2}{*}{ Kaynak } \\
\hline & pH & $\begin{array}{c}\text { Biyosorbent } \\
\text { miktarı } \\
(\mathrm{g} / \mathrm{L})\end{array}$ & $\begin{array}{l}\text { Temas } \\
\text { süresi } \\
\text { (dak) }\end{array}$ & $\begin{array}{c}\text { Sicaklık } \\
\left({ }^{\circ} \mathrm{C}\right)\end{array}$ & $\begin{array}{c}\text { Derişim } \\
\text { (mg/l) }\end{array}$ & & \\
\hline Fındıkkabuğu & $2,5-4,2$ & 10 & 360 & 20 & $50-1000$ & 76,9 & {$[24]$} \\
\hline Pirinç kabuğu & 8 & 1,2 & 2880 & 32 & $10-125$ & 40,6 & {$[25]$} \\
\hline Buğday kabuğu & 8 & 0,625 & 300 & 23 & $1,4-14$ & 26,1 & [26] \\
\hline Susam kabuğu & 5,5 & 2 & 120 & 30 & $100-450$ & 359,8 & [27] \\
\hline Hurma çekirdeği & 6,3 & 10 & 240 & 70 & $70-700$ & 43,5 & {$[28]$} \\
\hline Çay atığ 1 & 8 & 1,5 & 360 & 27 & $10-50$ & 85,2 & [29] \\
\hline Muz kabuğu & 7,2 & 1 & 1440 & 30 & $10-120$ & 20,8 & {$[30]$} \\
\hline Nohut samanı & 7 & 1 & 180 & 50 & $100-400$ & 108,7 & Bu çalışma \\
\hline
\end{tabular}


adımda meydana gelmektedir. Sınır tabakasındaki adsorpsiyon direnci, temas süresindeki artış ve adsorpsiyon hızı ile değişmektedir. Çünkü temas süresi arttıkça sınır tabaka direnci azalır ve adsorpsiyon hızının artmasıyla da boya moleküllerinin hareketliliği artar [31]. Çalışmada kullanılan kinetik modellerinin deneysel veriler ile uyumu Şekil 4'de verilmiştir. Partikül içi difüzyon modeline göre, çizilen doğru orijinden geçiyorsa, h1z kontrol basamağ1 partikül içi difüzyondur. Eğer, çizilen doğru orijinden geçmiyorsa, biyosorpsiyon esnasında hız kontrol basamağını sadece partikül içi difüzyonu etkilemediği, bununla beraber diğer kinetik modellerinin de hız kontrol basamağında etkisi olduğunu anlaşılmaktadır [22]. Elde edilen doğruya göre, metilen mavisinin nohut samanı üzerine biyosorpsiyonunda sadece partikül içi difüzyon değil, aynı zamanda yüzey adsorpsiyonunun da etkin olduğu sonucuna varılmaktadır. Farklı sıcaklıklar için kinetik modellere ait teorik ve hesaplanan $\mathrm{q}_{\mathrm{e}}$ değerleri ile kinetik hız sabitleri ve regresyon katsayıları ise Tablo 4'de verilmiştir. Şekil 4 ile Tablo 4 birlikte incelendiğinde, sözde 2. dereceden kinetik modeli için belirlenen regresyon katsayılarının, sözde 1 . dereceden ve partikül içi kinetik modelleri için hesaplanan değerlere göre daha yüksek olduğu ve sözde 2. dereceden modelin deneysel veriler daha uyumlu olduğu görülmüştür. $\mathrm{Bu}$ durum, metilen mavisi moleküllerinin nohut samanı üzerine tutulmasının, kimyasal adsorpsiyon ile gerçekleştiğini belirtmektedir [32,33].
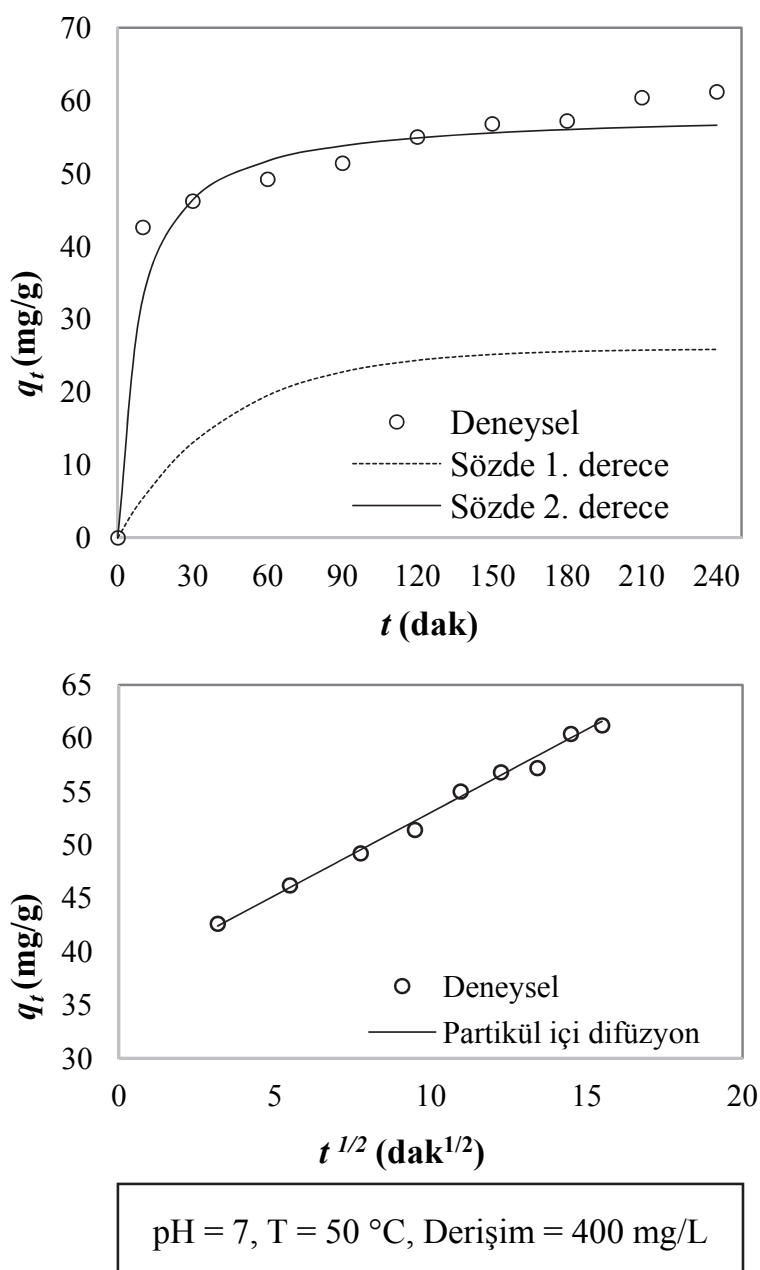

Şekil 4. Kinetik modellerin deneysel veriler ile uyumu (Fitting of kinetic models with the experimental data)

Tablo 4. Metilen mavisi biyosorpsiyona ait kinetik parametreler (Isotherm parameters for the methylene blue biosorption)

\begin{tabular}{|c|c|c|c|c|c|c|c|c|c|c|c|}
\hline \multirow[b]{2}{*}{$\mathbf{T}(\mathrm{K})$} & \multirow[b]{2}{*}{$\mathbf{C}_{\mathbf{0}}$} & \multirow[b]{2}{*}{$\mathbf{q}_{\mathrm{e}, \mathrm{teo}}$} & \multicolumn{3}{|c|}{ Sözde 1. dereceden } & \multicolumn{3}{|c|}{ Sözde 2. dereceden } & \multicolumn{3}{|c|}{ Partikül içi difüzyon } \\
\hline & & & $\mathbf{q}_{\mathrm{e}, \mathrm{hes}}$ & $\mathbf{k}_{1}$ & $\mathbf{R}^{2}$ & $\mathbf{k}_{\mathbf{2}}$ & $\mathbf{q}_{\mathrm{e}, \mathrm{hes}}$ & $\mathbf{R}^{2}$ & $\mathbf{k}_{\mathbf{p}}$ & $\mathbf{C}$ & $\mathbf{R}^{2}$ \\
\hline \multirow{4}{*}{20} & 100 & 14,06 & 5,08 & 0,009 & 0,5957 & 0,0092 & 12,95 & 0,9743 & 0,252 & 9,176 & 0,6183 \\
\hline & 200 & 27,12 & 7,82 & 0,010 & 0,9708 & 0,0059 & 26,17 & 0,9971 & 0,573 & 18,42 & 0,9497 \\
\hline & 300 & 38,20 & 7,55 & 0,010 & 0,9394 & 0,0074 & 37,17 & 0,9990 & 0,621 & 29,28 & 0,9110 \\
\hline & 400 & 47,60 & 36,45 & 0,023 & 0,8826 & 0,0012 & 50,50 & 0,9827 & 2,138 & 20,24 & 0,9713 \\
\hline \multirow{4}{*}{30} & 100 & 15,86 & 4,99 & 0,012 & 0,9885 & 0,0098 & 15,57 & 0,9984 & 0,421 & 10,168 & 0,9843 \\
\hline & 200 & 28,64 & 8,69 & 0,014 & 0,9885 & 0,0056 & 28,49 & 0,9982 & 0,699 & 19,314 & 0,9925 \\
\hline & 300 & 41,20 & 12,74 & 0,019 & 0,9172 & 0,0037 & 42,19 & 0,9985 & 0,851 & 30,143 & 0,9950 \\
\hline & 400 & 54,20 & 20,83 & 0,008 & 0,9738 & 0,0012 & 54,64 & 0,9810 & 1,658 & 29,082 & 0,9363 \\
\hline \multirow{4}{*}{40} & 100 & 15,98 & 4,27 & 0,0128 & 0,9725 & 0,0084 & 16,26 & 0,9975 & 0,3615 & 11,100 & 09639 \\
\hline & 200 & 29,16 & 8,40 & 0,0149 & 0,9798 & 0,0046 & 29,76 & 0,9981 & 0,6932 & 20,097 & 0,9852 \\
\hline & 300 & 42,00 & 8,16 & 0,0128 & 0,9759 & 0,0046 & 42,37 & 0,9986 & 0,6323 & 33,195 & 0,9986 \\
\hline & 400 & 54,20 & 29,08 & 0,0234 & 0,8876 & 0,0015 & 57,80 & 0,9937 & 1,7593 & 32,844 & 0,9588 \\
\hline \multirow{4}{*}{50} & 100 & 17,06 & 5,01 & 0,016 & 0,9630 & 0,0097 & 17,09 & 0,9976 & 0,377 & 12,066 & 0,9857 \\
\hline & 200 & 29,90 & 8,74 & 0,019 & 0,9566 & 0,0060 & 30,21 & 0,9981 & 0,657 & 21,649 & 0,9736 \\
\hline & 300 & 43,20 & 8,34 & 0,009 & 0,9709 & 0,0062 & 41,84 & 0,9987 & 0,654 & 33,528 & 0,9533 \\
\hline & 400 & 57,20 & 25,94 & 0,023 & 0,8751 & 0,0021 & 58,47 & 0,9957 & 1,554 & 37,488 & 0,9917 \\
\hline
\end{tabular}




\subsection{Termodinamik Çalışmalar (Thermodynamic Studies)}

Biyosorpsiyon işlemine ait termodinamik parametrelerden serbest enerji $\left(\Delta \mathrm{G}^{\circ}\right)$, entalpi $\left(\Delta \mathrm{H}^{\circ}\right)$ ve entropide $\left(\Delta \mathrm{S}^{\circ}\right)$ meydana gelen değişim aşağıda verilen eşitlik kullanılarak hesaplanmaktadır:

$$
\begin{aligned}
& \Delta G^{\circ}=-R T \ln K_{L} \\
& \Delta G^{o}=\Delta H^{o}-T \Delta S^{o}
\end{aligned}
$$

Eşitliğin matematiksel olarak düzenlenmesiyle termodinamik parametrelerin hesaplanabilmesi için aşağıda belirtilen formül elde edilir:

$$
\ln K_{L}=-\frac{\Delta G^{\circ}}{R T}-\frac{\Delta \mathrm{H}^{\circ}}{R T}+\frac{\Delta S^{\circ}}{R}
$$

Burada $\mathrm{K}_{\mathrm{L}}(\mathrm{L} / \mathrm{mg})$ Langmiur biyosorpsiyon sabiti, $\mathrm{R}$ $(8.314 \mathrm{~J} / \mathrm{mol} \mathrm{K})$ evrensel gaz sabiti ve $\mathrm{T}(\mathrm{K})$ mutlak sicaklıktır. Buna göre metilen mavisi biyosorpsiyonuna ait hesaplanan termodinamik parametreler $\left(\Delta \mathrm{G}^{\circ}, \Delta \mathrm{H}^{\circ}\right.$ ve $\left.\Delta \mathrm{S}^{\circ}\right)$ Tablo $5^{\prime} \mathrm{de}$ verilmiştir. Negatif değerdeki serbest enerji $\left(\Delta G^{\circ}\right)$, biyosorpsiyon işleminin kendiliğinden gerçekleştiğini göstermektedir. Biyosorpsiyon işlemine ait hesaplanan entalpi değerinin pozitif olması ise biyosorpsiyon işleminin $20-50{ }^{\circ} \mathrm{C}$ sıcaklıkları arasında endotermik olarak gerçekleştiğini desteklemektedir. Ayrıca, sistemin entropisinin pozitif olması, biyosorpsiyon esnasında katı-çözelti ara yüzeyindeki düzensizliklerin azaldığını belirtmektedir.

Tablo 5. Metilen mavisi biyosorpsiyonuna ait

\begin{tabular}{|c|c|c|c|c|}
\hline $\begin{array}{c}\mathbf{T} \\
(\mathbf{K})\end{array}$ & $\begin{array}{c}\Delta \mathrm{G}^{\circ} \\
(\mathrm{kJ} / \mathrm{mol})\end{array}$ & $\begin{array}{c}\Delta \mathbf{H}^{\circ} \\
(\mathrm{kJ} / \mathrm{mol})\end{array}$ & $\begin{array}{c}\Delta \mathbf{S}^{\circ} \\
(\mathrm{J} / \mathrm{mol})\end{array}$ & $\mathbf{R}^{2}$ \\
\hline 293 & $-18,24$ & \multirow{4}{*}{15,83} & \multirow{4}{*}{116,56} & \multirow{4}{*}{0,964} \\
\hline 303 & $-19,69$ & & & \\
\hline 313 & $-20,65$ & & & \\
\hline 323 & $-21,78$ & & & \\
\hline
\end{tabular}
termodinamik parametreler (Thermodynamic parameters for the methylene blue biosorption)

Biyosorpsiyon işleminin aktivasyon enerjisi ise farklı sıcaklıklarda elde edilen veriler kullanılarak aşağıda verilen formül ile hesaplanabilir:

$$
\ln k_{2}=\ln A-\frac{E_{a}}{R T}
$$

Belirtilen formülde $\mathrm{k}_{2}$ (g/mg dak) sözde 2.dereceden kinetik hız sabitinden faydalanarak elde edilen, $\ln$ $\mathrm{k}_{2}$ 'ye karşılık 1/T grafiğinden hesaplanan aktivasyon enerjisi $\left(E_{a}\right)$ yaklaşık olarak $17 \mathrm{~kJ} / \mathrm{mol}$ olarak bulunmuştur. Genel olarak aktivasyon enerjisi 4,2 $\mathrm{kJ} / \mathrm{mol}$ 'den düşük bulunduğunda fiziksel, 8,4 ile 83,7 $\mathrm{kJ} / \mathrm{mol}$ aralığında bulunduğunda ise kimyasal adsorpsiyon olduğu bilinmektedir [34]. Bu çalışmada hesaplanan aktivasyon enerjisinin değerinin kimyasal adsorpsiyon için belirtilen aralıkta bulunması, 20 ile $50^{\circ} \mathrm{C}$ sicaklıkları arasında nohut samanı üzerine metilen mavisi tutunması işleminin kimyasal adsorpsiyon ile gerçekleştiğini desteklemektedir.

\section{SONUÇLAR (CONCLUSIONS)}

Yapılan bu çalışmada biyosorbent olarak kullanılan nohut samanı ile sulu çözeltilerden metilen mavisi giderimi incelenmiştir. Deneysel sonuçlar çözelti sıcaklığının artmasıyla biyosorpsiyon veriminin arttığını ve $180 \mathrm{dk}$ sonunda sistemin dengeye yaklaştığını göstermiştir. Kinetik ve izoterm hesaplamalar ile metilen mavisi biyosorpsiyonunun sözde 2. derece kinetik modele, denge halindeki sistemin ise Freundlich izotermine uyduğu tespit edilmiştir. Termodinamik çalışmalar sonucunda ise biyosorpsiyon işleminin kendiliğinden gerçekleştiği ve giderim esnasında katı ve çözelti arasındaki ara yüzeydeki düzensizliğin azaldığı belirlenmiştir. Metilen mavisi biyosorpsiyonu için maksimum tek tabaka biyosorpsiyon kapasitesi ise $108,7 \mathrm{mg} / \mathrm{g}$ olarak belirlendiği çalışmanın sonucunda, nohut samanının sulu çözeltilerden boyar madde gideriminde çevreye dost, düşük maliyetli ve etkili bir biyosorbent olarak kullanılabileceği belirlenmiştir.

\section{KAYNAKLAR (REFERENCES)}

1. Doğan, M., Abak, H. ve Alkan, M., "Adsorption of Methylene Blue onto Hazelnut Shell: Kinetics, Mechanism and Activation Parameters", Journal of Hazardous Materials, Cilt 164, 172-181, 2009.

2. Gökkuş, Ö. ve Çiner, F., "Dispers Sarı 119 Ve Dispers Kırmızı 167 İçeren Atıksuların Fenton Oksidasyon Prosesi İle Renk ve KOI Giderimlerinin İncelenmesi", Journal of the Faculty of Engineering and Architecture of Gazi University, Cilt 25, No 1, 49-55, 2010.

3. Aroguz, A.Z., Gulen, J. ve Evers, R.H., "Adsorption of Methylene Blue form Aqueous Solution on Pyrolyzed Petrified Sediment", Bioresource Technology, Cilt 99, 1503-1508, 2008 .

4. Aksu, A., Murathan, A. ve Koçyiğit, H., "Reaktif Mavi 221'in Pomza ile Adsorpsiyoin Kinetiği”, Journal of the Faculty of Engineering and Architecture of Gazi University, Cilt 26, No 4, 807-812, 2011.

5. Murathan, A. ve Koçyiğit, H., "Sulu Çözeltilerden Kadmiyum İyonlarının Dolgulu Yataklarda At Kestanesi ve Meşe Palamudu Kullanilarak Giderilmesi", Journal of the Faculty of Engineering and Architecture of Gazi University, Cilt 28, No 2, 303-306, 2013.

6. Türkiye Cumhuriyeti Başbakanlık Yatırım Destek ve Tanıtım Ajansı, "Türkiye Tarım Sektörü Raporu”, Temmuz 2010, 
http://www.invest.gov.tr/trTR/infocenter/publica tions/Documents/TARIM.SEKTORU.PDF

7. Food and Agriculture Organisation of United Nations(FAO), “Tarım Ürünlerin Dünya İstatistikleri", Aralık 2012, www.fao.org

8. Han, R., Zou, W., Yu, W., Cheng, S., Wang, Y. ve Shi, J., "Biosorption of Methylene Blue from Aqueous Solution by Fallen Phoenix Tree's Leaves", Journal of Hazardous Materials, Cilt 141, 156-162,2007.

9. Ghaedi, M., Hajati, S., Barazesh, B., Karimi, F., Ghezelbash, G., "Saccharomyces cerevisiae for the biosorption of basic dyes from binary component systems and the high order derivative spectrophotometric method for simultaneous analysis of Brilliant green and Methylene blue", Journal of Industrial and Engineering Chemistry, Cilt 19, 227-233, 2013.

10. Aksu, Z., Ertuğrul, S., Dönmez, G., "Methylene Blue biosorption by Rhizopus arrhizus: Effect of SDS(sodium dodecylsulfate) surfactant on biosorption properties", Chemical Engineering Journal, Cilt 158, No 3, 474-481, 2010.

11. Han, R., Wang, Y., Han, P., Shi, J., Yang, J., Lu, Y., "Removal of methylene blue from aqueous solution by chaff in batch mode", Journal of Hazardous Materials, Cilt 137, No 1, 550-557, 2006.

12. Pavan, F.A., Lima, E.C., Dias, S.L.P., Mazzocato, A.C., "Methylene blue biosorption from aqueous solutions by yellow passion fruit waste", Journal of Hazardous Materials, Cilt 150, No 3, 703-712, 2008.

13. Xiao, X., Luo, S., Zeng, G., Wei, W., Wan, Y., Chen, L., Guo, H., Cao, Z., Yang, L., Chen, J. ve Xi, Q., "Biosorption of Cadmium by Endophytic Fungus(EF) Microsphaeropsis Sp. LSE10 İsolated from Cadmium Hyperaccumulator Solanum Nigrum L.”, Bioresource Technology, Cilt 101, 1668-1674, 2010.

14. Al-Anber, Z.A., Al-Anber, M.A., Matouq, M., Al-Ayed, O., Omari, N.M., "Defatted Jojoba for the removal of methylene blue from aqueous solution: Thermodynamic and kinetic studies", Desalination, Cilt 276, No 1-3, 169-174, 2011.

15. Cherifi, H., Fatih, B., Salah, H., "Kinetic studies on the adsorption of methylene blue onto vegetal fiber activated carbons", Applied Surface Science, Cilt 282, 52-59, 2013.

16. Akkurt, F., Alıcılar, A., Şendil, O., "Sularda Bulunan Nitratın Adsorpsiyon Yoluyla Uzaklaştırılması", Journal of the Faculty of Engineering and Architecture of Gazi University, Cilt 17, No 4, 83-91, 2002.

17. Langmuir, I., "The Constitution and Fundamental Properties of Solids and Liquids", Journal of American Chemical Society, Cilt 38, 2221-2295, 1916.
18. Freundlich, H.M.F., "Über die Adsorption in Lösungen", Zeitschrift für Physikalische Chemie, Cilt 57, 385-470, 1906.

19. Dubinin, M.M. ve Radushkevich, L.V., "Equation of the Characteristic Curve of Activated Charcoal", Proceedings of the USSR Academy of Sciences Physical Chemistry, Cilt 55, 331, 1947.

20. Lagergren, S., "Zur theorie der sogenannten adsorption geloster stoffe", Kungliga Svenska Vetenskapsakademiens, Handlingar, Cilt 24, 1-39, 1898.

21. Ho, Y.S., McKay, G., "Pseudo-Second Order Model for Sorption Process", Process Biochemistry, Cilt 34, 451-465, 1999.

22. Weber, W.J., Morriss, J.C., "Kinetics of Adsorption on Carbon From Solution", Journal of the Sanitary Engineering Division American Society of Civil Engineers, Cilt 89, 31-60, 1963.

23. Amini, M., Younesi, H., Bahramifar, N., "Biosorption of nickel(II) from aqueous solution by Aspergillus niger: Response surface methodology and isotherm study", Chemosphere, Cilt 75, No 11, 1483-1491, 2009.

24. Ferrero, F., "Dye Removal by Low Cost Adsorbents: Hazelnut Shells in Comparison with Wood Sawdust", Journal of Hazardous Materials, Cilt 142, 144-152, 2007.

25. Vadivelan, V., Vasanth Kumar K., "Equilibrium, kinetics, mechanism, and process design for the sorption of methylene blue onto rice husk", Journal of Colloid and Interface Science, Cilt 286, No 1, 90-100, 2005.

26. Batzias, F., Sidiras, D., Schroeder, E., Weber, C., "Simulation of Dye Adsorption on Hydrolyzed Wheat Straw in Batch and FixedBed Systems", Chemical Engineering Journal, Cilt 148,459-472, 2009.

27. Feng, Y., Yang, F., Wang, Y., Ma, L., Wu, Y., Kerr P.G., Yang, L., "Basic Dye Adsorption onto an Agro-Based Waste Material-Sesame Hull(Sesamum İndicum L.)", Bioresource Technology, Cilt 102, 10280-10285, 2011.

28. Belala. Z., Jeguirim, M., Belhachemi,M., Addoun, F., Trouvé, G., "Biosorption of Basic Dye from Aqueous Solutions by Date Stones and Palm-Trees Waste: Kinetic, Equilibrium and Thermodynamic Studies", Desalination, Cilt 271, 80-87, 2011.

29. Uddin, M.T., Islam, M.A., Mahmud, S., Rukanuzzaman, M., "Adsorptive Removal of Methylene Blue by Tea Waste", Journal of Hazardous Materials, Cilt 164, 53-60, 2009.

30. Annadurai, G., Juang, R.S., Lee, D.J., "Use of cellulose-based wastes for adsorption of dyes from aqueous solutions", Journal of Hazardous Materials, Cilt 92, No 3, 263-274, 2002. 
31. Doğan, M., Özdemir, Y., Alkan, M., "Adsorption kinetics and mechanism of cationic methyl violet and methylene blue dyes onto sepiolite", Dyes and Pigments, Cilt 75, Sayı 3, 701-713, 2007.

32. Hamayun, M., Mahmood, T., Naeem, A., Muska, M., Din, S.U., Waseem, M., "Equilibrium and kinetics studies of arsenate adsorption by $\mathrm{FePO}_{4}$ ", Chemosphere, Cilt 99, 207-215, 2014.

33. Huang, W.Y., Li, D., Liu, Z.Q., Tao, Q., Zhu, Y., Yang, J., Zhang, Y.M., "Kinetics, isotherm, thermodynamic, and adsorption mechanism studies of $\mathrm{La}(\mathrm{OH})_{3}$-modified exfoliated vermiculites as highly efficient phosphate adsorbents", Chemical Engineering Journal, Cilt 236, 191-201, 2014.

34. Dursun, A.Y., "A comparative study on determination of the equilibrium, kinetic and thermodynamic parameters of biosorption of copper(II) and lead(II) ions onto pretreated Aspergillus niger", Biochemical Engineering Journal, Cilt 28, No 2, 187-195, 2006. 